Presented at the 321 st Meeting of the Ameri;an Institute of Electrical Engineers, Washington, D. C., A pril 26, 1916.

Copyright 1916. By A. I. E. E.

\title{
WATER POWER AND DEFENSE
}

\author{
BY W. R. WHITNEY
}

Abstract of Paper

The United States has no adequate domestic source of fixed nitrogen. Nitric acid is an absolute necessity in the manufacture of any form of explosive as well as in the production of dye stuffs. Ammonia or nitrate compounds are in increasing demand as fertilizers. The present dependence upon Chile is a menace in case of war and involves the payment of export duties and profits amounting to nearly $\$ 5,000,000$ annually in times of peace.

Home production is wholly a question of initiative and proper utilization of water power. Failure to establish the industry in the past has been due to economic conditions, such as the relative proximity of Chile and the impossibility of competing with the cheap water powers of Scandinavia as well as the lack of a near-by agricultural demand. The growing need for fertilizers, the desirability of establishing a dye-stuff industry and especially the feeling of uncertainty in international relations make a reconsideration desirable.

National safety demands the development of a nitrogen fixation industry whether it be self-supporting or not. But, the industry once established, the products would be of the greatest value in times of peace and many other industries would be stimulated thereby. Thorough industrial organization is the best preparedness for either peace or war.

Each of the processes under consideration has advantages. The problem is many-sided and far reaching and hence it is very desirable that the various government departments concerned, those of the Army, Navy, Agriculture, and Interior, with their skilled staffs and expert knowledge, should cooperate in determining the course to be taken. Immediate action is very important, since at least two years will be consumed in getting any process available into operation, after a decision is reached.

EWS on the relationship between our water power problems and the problems of national defense are as different as they are numerous. No one is safe in assuming that he has, for long, held the correct view, for the correct view changes rapidly with the conditions, and these changing conditions are not entirely under control. There are a few facts which it may be wise to review because of the changing conditions referred to, and because all of us are interested in national welfare.

A group of these facts which relate to what we call fixed 
nitrogen should be foremost in our interest: They may be briefly stated as follows. The United States has thus far practically no natural sources of niter or other form of fixed nitrogen, nor has it developed any sources of the artificial products beyond the recovery of ammonia from gas-liquors and coke ovens.

Niter has always been the sine qua non of explosives, and with all the complicated developments which have taken place in the field of explosive manufacture, nothing practical has been produced which does not depend absolutely upon niter.

The old type black gunpowder which contained niter, sulphur and charcoal, used the salt as such. The later smokeless powders made use of the nitric acid produced from niter by means of sulphuric acid. The cellulose, the glycerine, and the toluol in gun cotton, nitroglycerine and trinitrotoluol respectively, are wonderful substitutes for the sulphur and charcoal of the former explosives, but what we may call the pepper in the powder has always been the nitro group from the niter.

This means, to those who are considering the question of preparedness for defense, that our sources of niter need a lot of insurance. It is not at all inconceivable that our present available supply of niter in South America might become closed to us in the event of war.

The problem of a home source of niter is an old one in the United States. The material has long been used by our fertilizer industries. Organizations representing agricultural interests have tried to bring about reduction in cost of fertilizer necessities - phosphate, potash, and nitrate or ammonia. We have plenty of phosphate rock in the United States, so that freight rates will apparently be the determining factor in the extent of use of this fertilizer ingredient. In the case of potash we are in bad shape. We have some unlocked sources, but nothing comparable with the German supply. We must learn how to cheaply separate potash from our feldspars, our seaweeds, or our ocean waters, and there seems little chance that this will be economically done very soon.

But when it comes to nitrate and ammonia, it is distinctly up to us. The cost will depend on the way in which we use our water power. The raw materials come from the air and the water, and ought to be free to us. At present we are subsidizing the Chilean government at the rate of $\$ 2.25$ per ton, or nearly one and one-half million dollars a year for export duty, besides paying a profit of five to ten dollars per ton to the producers. This amounts to, say, five million dollars annually. 
In addition to our fertilizer interests, the country has become greatly interested in the aniline dye and chemical industry question. No single chemical is so generally important to this industry as nitric acid, and with us it is all obtained from niter. This fact seems to be an additional reason for attempting to round up our local needs for fixed nitrogen, determine the advisable steps to take, and quickly take them.

It is practically true that the aniline dye industry is essential. to the manufacture of modern explosives. The identical materials which are developed for dyes, now constitute the basic ingredients of the picric acid, trinitrotoluol, and tetra nitro methyl aniline used in the present war. The coal tar products, the acids and the apparatus are common to both dyes and explosives. For this reason, if we are to be efficient, if we are to have plants capable of producing explosives in large quantities when needed, then those plants must be producing useful chemical and dye products in times of peace.

If it were only necessary to dam the small water courses and pump the air through some sort of simple apparatus, in order to get niter more cheaply, the work would be easy. The question is in reality very complicated. It has never seemed worth while to dam the waterways to make niter in this country. In the first place, our farms, except in certain long-tilled or special localities, have not fallen so low in productivity that it pays the farmers to meet the prevailing costs of artificial fertilizer. This condition is a continually changing one, and it is always changing in the one direction. We shall as surely have to come to the extensive use of artificial fertilizer as have all the older countries. Our western grain and corn states are now producing only about half as much per acre as are the eastern states, and the difference is in fertilization.

Secondly, we have been able thus far to procure Chilean niter for our limited explosive and chemical manufacture, while the processes for obtaining nitrogen compounds from the air have been in a state of flux or development. It was a peaceful worldeconomy which established the first prartically operative and successful nitrate plant in Scandinavia. There such plants are close to the cheapest water powers, remote from all other sources of nitrate, and near the best markets. Norway's water powers differ essentially from our own. Nowhere in the United States, not even at Niagara, are there existing grouped conditions such as could compete successfully for cost of power with Norway. 
This is not generally remembered, but to engineers it should be plain. In Norway there was the fortunate combination of exceedingly elevated water level, of quite dependable and high rate of uninterrupted flow, with immediate ocean shipping facilities and a world's hemisphere of well established market close at hand. An expensive dam, or any dam at all was frequently unnecessary. Building sites were probably donated. Fertilizers were most extensively used and most of the world's chemicals and dye stuffs were made in the adjacent countries. Under such conditions there was apparently no reason for our country's doing this work, and that is why it has not been done.

It is the new conditions which make reconsideration worth while. One of these new conditions is our recently acquired feeling of uncertainty as to the permanence of peace. Another is our growing need for fertilizers, and a third, our desire to insure our textile industries by producing our own dyes and chemicals. Probably every human being on the earth today who has reflected at all, has been astounded at changes which a few months have produced in the most civilized countries of the world. It is not surprising that some of us should look about more or less nervously to see if our powder is all right.

Judging by past events, I think we are justified in imagining conditions which might effectively interfere with our continued supply of Chilean niter. Difficulties might arise before the salt is mined, as was the case with potash in Germany before the war. Transportation troubles from interference on the ocean, or trouble in Panama might be effective in shutting off our supplies. Perhaps the danger is slight, but if our importations of niter should cease, then all our efforts at dye stuff manufacture would fail, and all our efforts at national defense, beginning with diplomacy and ending with torpedoes, would be as useless as a poem on Spring. If we cannot shoot a gun, explode a mine or fire a torpedo without nitrate, we ought to be sure of our nitrate before we are forced into war. We need powder before we need soldiers or guns. Evidently this is a matter for mature deliberation on the part of those best fitted to weigh the possibilities.

Our requirements seem to suggest some early and effective type of cooperation between the department of the Interior, the Agricultural Department, the Army and the Navy, which departments are most intimately interested and best equipped to form opinions on the separate parts of this subject.

It is not my intention to consider the different ways of making 
nitrates, but a few words will show how rapidly the industry has recently advanced.

Since the experiments of Bradley and Lovejoy at Niagara, the Birkeland-Eyde electrical process has come into extensive commercial use in Norway. The Schonherr process, another arc process, has been developed in Germany, and the Pauling process in Austria. The cyanamid and Haber processes for ammonia combined with some form of the Ostwald process for changing ammonia to nitric acid, have both contributed to Germany's nitrate needs. The cyanamid process, using electrical power for making the calcium carbide, which is later employed for chemically combining the nitrogen of the air, was said in 1914 to be represented by 14 different plants, representing an investment of $\$ 30,000,000$. Since the beginning of the war, this process has been greatly augmented, apparently beyond any other. At the present time, Germany is probably using artificial nitrates exclusively, and the allies are beginning to employ them to a lesser extent.

It is because no group of our national representatives is likely to know all aspects of the nitrogen fixation problem, that the assistance of different interests and departments seems worth acquiring. It seems certain that our demand for nitrates for use in fertilizers, in heavy chemicals, pharmaceuticals, and dyes in time of peace, together with our possible needs for ammunition in times of war, would justify radical steps which any one of these apparent demands, taken alone, might not warrant. It is also probable that if our peace needs were properly taken care of, our war needs would be assured by the identical plants and processes.

It has been suggested that in an emergency, our electric street car and city lighting plants could quickly be turned into nitrate producers. A suggestion of this sort should be analyzed for our government by those competent to judge of the possibilities, and not be left to analysis by a pitiless fate.

It may be worth while to offer an opinion on a few of the questions naturally asked nowadays by the engineer concerning the possibilities of nitrate production in the United States. In times of peace and with present synthetic processes, commercial success is not possible if the electrical power costs are as high as fifteen dollars per kilowatt-year, and there are no profitable byproducts. At about half of this rate one or more of the present processes might possibly compete with the natural ante-bellum 
prices. This could not be done by the use of small isolated plants, nor less than full day load of power. In other words, it would not attract those who ordinarily sell electric power.

This is not the nation's question, however. It is more a question of whether, in times of dire necessity, we could at some inconvenience and high cost, effectively produce within a reasonable time our own requirements of niter. Could a part of existing electrical equipment be quickly utilized for this purpose? Under such conditions would a part-day load be permissible? Could coal be used for power? I do not answer as an expert, but I think that we may safely say that it would take us a couple of years to get under way with the manufacture on any appreciable scale after the delays which would certainly be connected with our decision to start, were passed. The cost might not be relatively greater than are the increased costs of many other products during war time. Electrical equipment already installed might in some cases be employed, but in all probability this would be calledupon for other uses with greater advantage to the country. As most of our industrial plants would have to do what they could best do, it seems probable that entirely new plants for nitrate would be called for. I believe this has been the experience abroad. In any of the synthetic processes, extensive and special types of apparatus are necessary: special transformers, special combustion chambers, large capacity air-liquefiers, etc. In the absence of water power such a plant could operate on steam power, but should be placed as near as possible to a coal supply. The possibility of utilizing waste coal, if there is any such thing nowadays, is worth looking into in connection with this question. It does not seem probable that part-time load is practicable even in war time, for the production of nitrate. By the arc process, something like three kilowatt-years may produce a ton of nitric acid, but when the demand amounts to two or three hundred thousand tons of acid per year under war conditions, and requires in that case the twenty-four-hour continual operation of over half a million kilowatts, the impracticability of getting any appreciable proportion of it from the offpeak power of present plants seems apparent. It is only fair to note that one of the processes is said to produce the acid at nearly a sixth of this consumption of power. But in this case, the operation in conjunction with existing power plants seems still less possible on account of the nature of the process.

Nowadays the essentials of national preparedness seem to 
require longer periods for accomplishment than formerly. When it takes years to build a battleship, war is not a brief siege. The art of successful defense has become a slow and subtle one. It starts with the high school and the education of children. It gets its main strength from the masterly control of technical industries. It owes its effectiveness to novelties in ways of killing, and its staying powers to business foresight and discreet banking policies. It has been well said in this connection that "there is one line of action which we ought to begin at once, and that is, we should begin at the bottom and prepare our industries."

It has also been pointed out that, strangely enough, many of the most useful modern chemical requirements of war are also the leading chemical products of the industries of peace. The chemist sees that sulphuric and nitric acids, chlorin, caustic soda, gasoline, benzol, phenol and toluol, perhaps the most industrial of the compounds in peace, are also the most extensively required in modern war. Similarly, the engineer knows that the modern air hardening tool steels, the modern lathes, the newest boring mills which industrial advance has developed, are now the necessities of munition production. So that industrial activity is a healthy type of national preparedness for both peace and defense.

But for national preparedness, our industrial activities should be comprehensive and cooperative. Whole fields of national interests should not be left entirely untouched because some other country is already profiting in them, as in the case of nitrates today. When it comes to national defense, we must ask ourselves what necessary supplies may be cut off by war. It is for this reason that England, Australia, Canada and Japan have already established national research organizations.

Preparing for defense is consistent with keeping at work in a proper way along the lines of peaceful, healthy industry. In this way it bears on the subject of water power. The engineer will always have the feeling that the power of falling water is a continuing loss except when it is doing useful work. This is inseparably connected with his first lessons in mechanics and thermodynamics, and is probably right. If a single manufacturing company owned our farms and waterways, it is probable that for reasons of efficiency it would make all the available falling water do the work needed to maintain the fertility of the soil or produce useful products. This would only be doing in a broader way what the potentates of Egypt and Assyria had to do cen- 
turies ago, when their irrigating systems were built. But we live under a representative form of government, where the difficulties and delay of getting constructive activity are what it costs us to be democratic.

At least two great processes for fixation of nitrogen have been offered to our government in the past few weeks. I refer to the arc process of the du Pont Company and the cyanamid process of the Cyanamid Company. These are essentially different. No brief discussion can bring out their relative values to our country. I consider both of them of the greatest importance to us.

The duPont process, yielding nitric acid directly from the air, calls for cheap water power. Used in conjunction with the production of explosives and the manufacture of chemicals and dye stuffs, it would be a great boon to America in times of peace, and invaluable in war time. The enormous facilities of such a company, widely interested in large scale chemical production and with one of the largest experimenting organizations in America, would certainly bring the arc process much nearer to that high condition of efficiency which the theory of the process predicts and which sometime will be realized somewhere-I hope in America. There is every reason to expect that there would result the evolution of as many new and useful products and processes as are being continually produced in Europe. Several hundred thousand kilowatts are now employed by the arc processes abroad.

The cyanamid process also calls for cheap waterpower and in large quantity. This process seems, at the present stage of things, to be of the greatest importance to our fertilizer industry because of its economical production of ammonia, the form of fixed nitrogen commonly used in commercial fertilizers. The manufacture of nitric acid and ammonium nitrate for explosives by this process is apparently easy and would be economical at power costs which we ought easily to reach in this country.

It is stated that there were somewhat over 200,000 h.p used by the cyanamid process abroad in 1914, and in the past eighteen months Germany has invested $\$ 100,000,000$. in this work.

These are both tested processes, and we are interested in their present, and even more particularly in their future developments. In any undertaking by our government which involves the granting of special water power rights, the people should want foresight coupled with active, constructive work. It seems as though we might fairly expect sometime a change in the public spirit, 
which now usually views almost any large manufacturing undertaking with animosity and adverse criticism. Possibly through the study of these immediately pressing problems of explosives, dyes and fertilizers by our most competent and interested government experts, sound business criteria may be established for the nation's benefit.

Personally, I have a fear that we are forever shortsighted. I am afraid of the need for national defense which may come upon us like a thief in the night, from war declared in a day, because I fear that impotency which is spread over a century and never really discovered until too late. The most imperilled country of the present war is learning more about national defense than we are at present, and is not likely to forget the lessons. New industrial processes will continue to be improved by those people who are now actively engaged in them. The more extended become the details, by-products, contingent interests and economies in any such line of industry, the more difficult becomes the start in it by an outsider. It is not out of the question that ten years from now the commercial sources of nitrate will be Germany and Chili. The artificial processes will certainly be improved. The natural source will about as certainly deteriorate. What will we be doing in the meantime? It may be entirely safe to depend indefinitely on Chilean supply, but the question should be decided for our country by those who are responsible and will give it careful consideration.

I believe effective good could be accomplished by quick cooperation between those different government departments where lie the greatest direct interest and knowledge. One of these is the Department of the Interior, under which come the group of experts of the Bureau of Standards and the Bureau of Mines. These certainly possess men interested in industrial chemistry, well equipped, and anxious to serve. The Bureau of Soils of the Department of Agriculture has also a corps of men equally well fitted for this work, and particularly interested to that part of it referring to the fertilizer problems. The Army and Navy Departments, busied with the multitude of normal duties of defense, might still lend a great deal of aid and pressure to this cooperative problem, without having to produce the same kind of chemical and engineering experts found in the other departments. The country ought to be satisfied with the joint conclusions of such representatives of its interests. 